\title{
Best Oxygenation Index on Day 1: A Reliable Marker for Outcome and Survival in Infants with Congenital Diaphragmatic Hernia
}

\author{
Elke Ruttenstock ${ }^{1} \quad$ Naomi Wright $^{2} \quad$ S. Barrena ${ }^{3}$ Annika Krickhahn ${ }^{4}$ Christoph Castellani ${ }^{1}$ \\ Ashish P. Desai ${ }^{5}$ Risto Rintala ${ }^{4}$ Juan Tovar ${ }^{3}$ Holger Till ${ }^{1}$ Augusto Zani ${ }^{2}$ Amulya Saxena ${ }^{1}$ \\ Mark Davenport ${ }^{2}$
}

\footnotetext{
${ }^{1}$ Department of Pediatric and Adolescents Surgery, Medical University of Graz, Graz, Austria

2 Department of Paediatric Surgery, King's College Hospital, London, United Kingdom

${ }^{3}$ Cirugía Pediátrica, Hospital Universitario La Paz, Madrid, Spain

${ }^{4}$ Department of Paediatric Surgery, Hospital for Children and

Adolescents, Helsinki, Finland

${ }^{5}$ Department of Paediatric Surgery, King's College Hospital, Cheyene

Wing Denmark Hill London, London, United Kingdom
}

Address for correspondence Mark Davenport, ChM, Department of Paediatric Surgery, King's College Hospital, London, United Kingdom (e-mail: mark.davenport@nhs.net).

Eur J Pediatr Surg 2015;25:3-8.

\section{Abstract}

Keywords

- diaphragmatic hernia

- mortality

- prognostic indices

- best oxygenation index
Aim of the Study Severe lung hypoplasia and persistent pulmonary hypertension are the main determining factors of survival in infants with congenital diaphragmatic hernia $(\mathrm{CDH})$. The oxygenation index (ratio of delivered oxygen and its arterial level) closely reflects lung function. Single-institution studies have reported that best oxygenation index on day 1 of life (BOI-d1) is the most reliable postnatal predictor of survival in $\mathrm{CDH}$. The aim of this study was to evaluate the predictive value of BOI-d1 in four disparate high volume centers in Europe.

Methods A retrospective, multicenter study of infants with CDH born between 2000 and 2009 in four European tertiary institutions was conducted. Ethical approval was obtained from institutional review boards. Centers no. 1 and. 4 offered extracorporeal membrane oxygenation (ECMO), whereas center no. 3 offered fetal endoluminal tracheal occlusion (FETO) in fetuses defined as poor prognosis (lung-to-head ratio $[L H R] \leq 1.0$ and "liver-up" position). Prenatal LHR and perinatal variables, including gestational age, birth weight, defect side, liver position, $\mathrm{BOI}-\mathrm{d} 1$, and patch requirement, were analyzed. Receiver operating characteristic curves were used to determine cutoff values for continuous variables. Comparison was made between survivors and nonsurvivors using univariate analysis and logistic regression analysis, $p<0.05$ was considered significant.

Results A total of 235 infants (center no. 1, $n=29$; no. 2, $n=64$; no. 3, $n=113$; and no. $4, n=29)$ were included. One infant required (2\%) ECMO and $66(28 \%)$ had FETO. LHR was available in 83 patients (36\%). Overall survival (discharge from hospital) and 28day survival were $67.6 \%(n=159)$ and $72.3 \%(n=170)$, respectively. Univariate analysis showed that significant categorical predictors of 28-day survival were liver- received

May 20, 2014

accepted after revision

July 29, 2014

published online

January 5, 2015 (c) 2015 Georg Thieme Verlag KG

Stuttgart · New York
DOI http://dx.doi.org/ 10.1055/s-0034-1393960. ISSN 0939-7248. 
down position $(p<0.0001)$, LHR $>1(p=0.003)$, and primary repair $(p=0.02)$ but not defect side $(p=0.83)$. Area under the receiver operating characteristic (AUROC) curve for continuous variables; gestational age, birth weight, and BOI-d1 were 0.70 , 0.68 , and 0.88 , respectively. AUROC for BOI-d1 (28-day survival) was 0.91 and had sensitivities (73 and $91 \%$ ) and specificities (92 and $80 \%$ ) for cutoffs of 40 and 82 , respectively.

Conclusion This multicenter study showed, that except from the defect side, all the prenatal variables studied have predictive value but the most useful is BOI-d1. This is simple to calculate and represents an excellent marker for lung function and a reliable early postnatal predictor of survival.

\section{Introduction}

Congenital diaphragmatic hernia $(\mathrm{CDH})$ is a complex condition with an incidence of 1 to 5 per 10,000 live births in Western Europe. ${ }^{1,2}$ Survival rates have slowly improved from approximately 50 to perhaps 70 to $80 \%$ in most institutions although the proportion remains lower in those with a high proportion of antenatally referred patients. ${ }^{3-7}$ This is despite significant advances in neonatal intensive care and the widespread availability of extracorporeal membrane oxygenation (ECMO), inhaled nitric oxide (NO), and high frequency oscillatory ventilation (HFOV). ${ }^{7-9}$ More recently, fetal intervention has been proposed to try and prevent or even reverse lung hypoplasia. In particular, fetal endoluminal tracheal occlusion (FETO) has been shown to ameliorate and even reverse impaired lung growth by preventing the egress of liquid from the lung, and it is currently in use in some European centers. $^{10-12}$

Prediction of survival is important in CDH to identify the infants with an impaired prognosis, target resources, and aid parental counseling. A plethora of prenatal and postnatal indices have been described at one time or another and include fairly nonspecific indices of infant maturity at birth, such as gestational age and birth weight, ${ }^{13-15}$ presence of other congenital anomalies, ${ }^{16}$ and the side of the defect. ${ }^{17}$ More sophisticated fetal ultrasound-derived features, such as presence or absence of liver herniation, ${ }^{18}$ thoracic position of the stomach, and the measured lung-to-head ratio (LHR), ${ }^{19,20}$ have all attempted to quantify the effects of herniation on the ipsilateral lung. More recently, direct measurements of lung volume have also been reported by fetal magnetic resonance imaging. ${ }^{21,22}$

As soon as the infant is born, the effects of lung hypoplasia become immediately evident and this crucial element can be quantified. Thus, Apgar scores ${ }^{14,23}$ and achieved arterial blood gases (best $\mathrm{Po}_{2}$, best $\mathrm{PcO}_{2}$ ) on day 1 have long been evaluated individually, ${ }^{24}$ or in combination (e.g., Wilford Hall/ Santa Rosa index, CDH study group index). ${ }^{25,26}$ The oxygenation index (OI) belongs to the latter group and we have reported that the best achieved OI on day 1 of life (BOI-d1) proved to be an effective independent predictor in singlecenter series of infants with antenatally detected $\mathrm{CDH} .{ }^{27}$ The value of BOI, either as a standalone parameter or within a set of variables, has also been confirmed in other series to predict survival and plan CDH surgical repair, ${ }^{28,29}$ or to predict the need for ECMO in neonates with respiratory failure. ${ }^{30,31}$

The aim of this study was to evaluate the predictive value of BOI-d1 in $\mathrm{CDH}$ patients recruited from four disparate European centers.

\section{Materials and Methods}

A retrospective analysis of outcome was performed in all infants with $\mathrm{CDH}$ born between 2000 and 2009 in four European tertiary pediatric surgery centers following ethical approval from their institutional review boards. The centers included Hospital for Children and Adolescents, Helsinki, Finland (no. 1), Hospital Universitario La Paz, Madrid, Spain (no. 2); King's College Hospital, London, United Kingdom (no. 3), and Universitaetsklinikum Graz, Austria (no. 4).

Center no. 1 and no. 4 offer ECMO for selected infants. Including criteria for ECMO are birth weight $>2 \mathrm{~kg}$, gestational age $>38$ weeks, no intracranial hemorrhage, and failed maximal conventional ventilation treatment in center no. 1 , and the EURO $\mathrm{CDH}$ consortium guidelines for ECMO referral in center no. $4 .{ }^{8}$ Center no. 3 offered FETO for poor prognosis fetuses selected on the basis of LHR $(\leq 1.0)$ and "liver-up" position. ${ }^{27}$ Outcomes and some elements of their morbidity (e.g., tracheomegaly) from the FETO group in center no. 3 have previously also been reported. ${ }^{15,32}$

Prenatal ultrasound characteristics (second trimester LHR, hernial contents) were available from centers no. 1, 2, and 3. Perinatal variables included gestational age, birth weight, defect side, and need for prosthetic patch in those coming to surgery. BOI-d1 was calculated from the best blood gas on day 1 of life as follows:

\% Fractional inspired $\mathrm{O}_{2} \times$ mean airway pressure (in $\mathrm{cm}$ $\mathrm{H}_{2} \mathrm{O}$ ) $/ \mathrm{PaO}_{2}$ (in kPa). ${ }^{27}$

Survival was defined as overall survival and survival to 28 days. Comparison was made between survivors and nonsurvivors using univariate $\mathrm{X}^{2}$ analysis. Receiver operating characteristic (ROC) curves were used to determine cutoff values for continuous variables. Nonparametric statistical tests (e.g., Kruskal-Wallis test, Mann-Whitney U test, Spearman rank correlation) were used to determine differences between groups and any degree of association. Data are 
quoted as median (interquartile range [IQR]), $p<0.05$ was considered significant.

\section{Results}

There were 235 infants (center no. $1, n=29$; center no. 2, $n=64$; center no. $3, n=113$; and center no. $4, n=29$ ) within the study period. Of these, 136 (58\%) patients were male. An infant from center no. 4 had a 5-day period of ECMO while 66 infants from center no. 3 had undergone a FETO procedure. A total of 174 (74\%) infants underwent operative repair of $\mathrm{CDH}$ with 65 (37\%) requiring a prosthetic patch. There was a significant difference in the need for prosthetic patch across the centers (no. 1, 44\%; no. 2, 14\%; no. 3, 58\%; no. $4,27 \% ; p<0.001)$. Median gestational age at delivery was 38 (35-39) weeks. This varied across the centers $(p<0.0001)$ with center no. 3 having a significantly lower median gestation age (36 [34-38] weeks) than all others.

\section{Best Oxygenation Index (Day $\mathbf{1}$ )}

Median (IQR) BOI-d1 was 32 (18-91) and values were available in 189 infants. BOI-d1 was significantly lower in nonFETO than in FETO infants (29 [18-77] vs. 52 [21-153]; $p=0.023$ ) and in those who underwent primary repair compared with those requiring a prosthetic patch repair (21 [13-29] vs. 46 [22-81]; $p<0.0001)$. There was a low degree of inverse correlation between BOI-d1 and both birth weight $\left(r_{\mathrm{S}}=-0.12 ; p=0.05\right)$ and gestational age $\left(r_{S}=-0.16 ; p=0.01\right)$. There was a significant difference in BOI-d1 between the four centers (no. 1, 68 [29-92]; no. 2, 24 [12-47]; no. 3, 42 [22-156], and no. 4, 22 [18-41]; analysis of variance [ANOVA] $p<0.0001$ ) ( Fig. 1).

Prenatal values for LHR were available in $83(36 \%)$ infants and typically from the single center no. 3 . There was a significant inverse correlation between first measured LHR and BOI- $\mathrm{d} 1\left(\mathrm{r}_{\mathrm{S}}=-0.33 ; p<0.003\right)$. These could be separated into those who then underwent intervention and those who followed the natural course $\left(\mathrm{r}_{\mathrm{S}}=0.22 ; p=0.11\right.$ and $\left(\mathrm{r}_{\mathrm{S}}=\right.$ $-0.42 ; p=0.03$, respectively). Indeed there was no signifi-

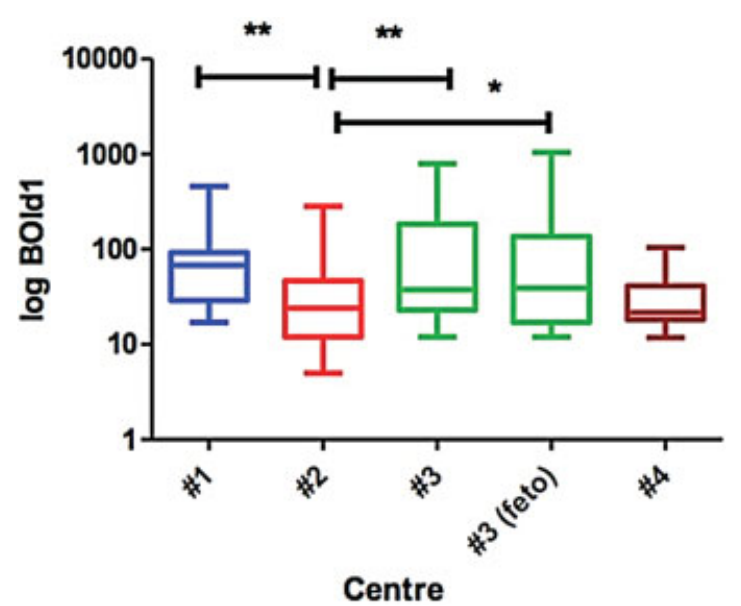

Fig. 1 Best oxygenation index on day 1 of life by center. ${ }^{*} p<0.05$, ${ }^{* *} p<0.01$.

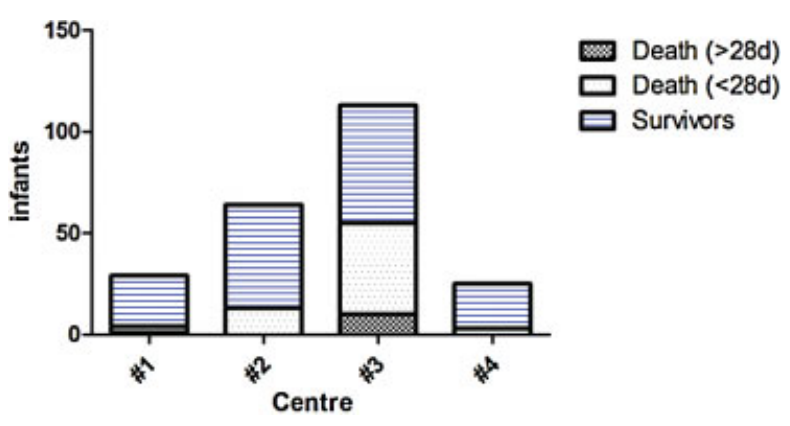

Fig. 2 Outcome of congenital diaphragmatic hernia by center.

cant difference between FETO and non-FETO infants (restricted to center no. 3 [52 \{21-153\} vs. $34\{22-199\} ; p=0.88]$ ).

\section{Outcome}

There were 76 (32.3\%) deaths ( $<28$ days $[n=65], \geq 28$ days $[n=11])$ in the series and of those, $23(30.3 \%)$ had undergone operative repair of the diaphragm. The overall survival (discharge from hospital) was $67.6 \%(n=159)$ and the 28 -day survival was $72.3 \%(n=170)$. This was chosen as the preferred outcome measure and varied by center from 60 (no. 3) to $90 \%$ (no. 1) (ANOVA $p<0.0001$ ) ( - Fig. 2).

\section{Prognostic Factors}

-Table 1 illustrates univariate $X^{2}$ analysis for the outcomesurvival to 28 days using categorical data and included "liverdown" position at fetal ultrasound $(p<0.0001)$ and need for primary repair $(p=0.02)$. There was no difference in outcome depending on the side of the diaphragm defect $(p=0.83)$.

-Table 2 illustrates the values for AUROC, sensitivities, and specificities for the continuous variables of gestational age and birth weight for overall survival and BOI-d1 both for overall and for survival to 28 days. The most useful predictive variable (for 28-day survival) was the BOI-d1 (AUROC, 0.91) ( - Fig. 3). Using a cutoff of $\leq 82$, the sensitivity was $91 \%$ ( $95 \%$ confidence interval $[\mathrm{Cl}], 85-95 \%$ ) and specificity was $80 \%$ (95\% CI, 66-90\%). Using a cutoff of $<40$, the sensitivity fell to $73 \%(95 \% \mathrm{CI}$, $65-$ $81 \%$ ) and specificity rose to $92 \%$ (95\% CI, $81-98 \%$ ).

Table 1 Categorical variables in congenital diaphragmatic hernia

\begin{tabular}{|c|c|c|c|}
\hline Variable & $n$ & $\begin{array}{l}\text { 28-day } \\
\text { survival (\%) }\end{array}$ & $p$-Value \\
\hline \multicolumn{4}{|l|}{ Fetal variables } \\
\hline $\begin{array}{l}\text { Liver position } \\
\text { (down/up) }\end{array}$ & $89 / 100^{a}$ & 88 vs. $62 \%$ & $<0.0001$ \\
\hline $\begin{array}{l}\text { Side } \\
\text { (left/right) }\end{array}$ & $198 / 31^{b}$ & 73 vs. $71 \%$ & 0.83 \\
\hline \multicolumn{4}{|l|}{ Postnatal variables } \\
\hline $\begin{array}{l}\text { Surgery (primary/ } \\
\text { patch repair) }\end{array}$ & $109 / 65$ & 96 vs. $88 \%$ & 0.03 \\
\hline
\end{tabular}

${ }^{\mathrm{a}}$ Total excludes missing data; $p<0.05$.

${ }^{\mathrm{b}}$ Total excludes bilateral congenital diaphragmatic hernia or missing data; $p<0.01$. 
Best Oxygenation Index on Day 1 Ruttenstock et al.

Table 2 Continuous variables in congenital diaphragmatic hernia

\begin{tabular}{|c|c|c|c|c|c|}
\hline Variable & Predicted survival & $\begin{array}{l}\text { AUROC } \\
\text { (95\% CI) }\end{array}$ & Cutoff & $\begin{array}{l}\text { Sensitivity (\%) } \\
(95 \% \mathrm{Cl})\end{array}$ & $\begin{array}{l}\text { Specificity (\%) } \\
(95 \% \mathrm{Cl})\end{array}$ \\
\hline Gestational age (wk) & Overall & $\begin{array}{l}0.70 \\
(0.62-0.78)\end{array}$ & 34 & $\begin{array}{l}42 \\
(30-55)\end{array}$ & $\begin{array}{l}89 \\
(84-94)\end{array}$ \\
\hline Birth weight (kg) & Overall & $\begin{array}{l}0.68 \\
(0.60-0.76)\end{array}$ & 2.5 & $\begin{array}{l}51 \\
(38-64)\end{array}$ & $\begin{array}{l}75 \\
(68-82)\end{array}$ \\
\hline \multirow[t]{4}{*}{ BOI-d1 } & \multirow[t]{2}{*}{ Overall } & \multirow[t]{2}{*}{$\begin{array}{l}0.88 \\
(0.82-0.94)\end{array}$} & 82 & $\begin{array}{l}94 \\
(88-97)\end{array}$ & $\begin{array}{l}73 \\
(60-84)\end{array}$ \\
\hline & & & 40 & $\begin{array}{l}75 \\
(66-82)\end{array}$ & $\begin{array}{l}85 \\
(73-93)\end{array}$ \\
\hline & \multirow[t]{2}{*}{$28 \mathrm{~d}$} & \multirow[t]{2}{*}{$\begin{array}{l}0.91 \\
(85-96)\end{array}$} & 82 & $\begin{array}{l}91 \\
(85-95)\end{array}$ & $\begin{array}{l}80 \\
(66-90)\end{array}$ \\
\hline & & & 40 & $\begin{array}{l}73 \\
(65-81)\end{array}$ & $\begin{array}{l}92 \\
(81-98)\end{array}$ \\
\hline
\end{tabular}

Abbreviations: AUROC, area under the receiver operating characteristic; $\mathrm{BOI}-\mathrm{d} 1$, best oxygenation index on day 1 of life; $\mathrm{Cl}$, confidence interval.

\section{Comparison of Centers}

To examine whether BOI-d1 was also applicable outside of the originating center (no. 3 ), we repeated the prediction of 28-day survival using data from the other three centers (no. 1, 2, and 4). This showed entirely comparable results with an AUROC of 0.94 (95\% CI, 90-98\%). The relevant sensitivity and specificity for a cutoff of 82 was $86(95 \% \mathrm{CI}$, $71-95 \%)$ and 89 (80-94\%); and a cutoff of 40 was 97 (86-99.9\%) and 67 (56-77\%).

To try and correct for the effect of FETO in center no. 3 when looking at BOI-d1, center no. 3 was divided according to whether patients had undergone FETO. This showed that the lowest BOI-d1 was in center no. 4 and the highest in center no. 1 (overall $p<0.0001$ ) (-Fig. 1).

\section{Discussion}

We have previously shown in a single-center retrospective series that BOI-d1 is a consistent, independent predictor of survival in $\mathrm{CDH} .{ }^{27}$ Further data from that center were combined with three other European centers and have shown a similar robust relationship between this and the relevant early outcome of 28-day mortality. We chose this as a preferable index and a more appropriate outcome measure

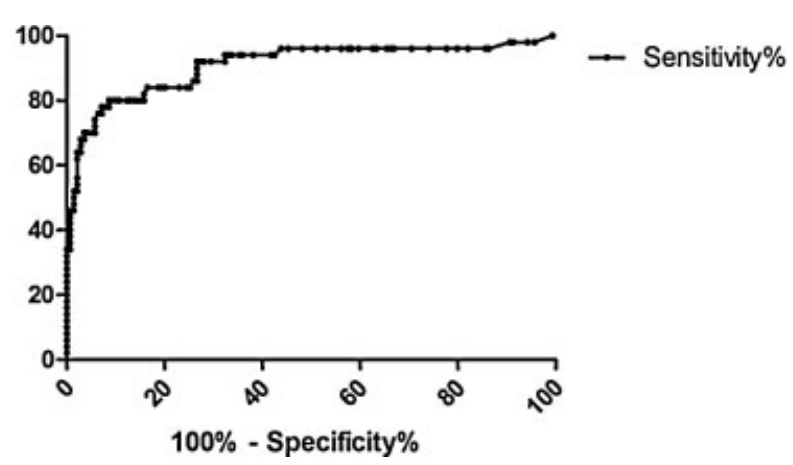

Fig. 3 Receiver operating characteristic curve of best oxygenation index on day 1 of life across four centers $(n=189)$. Prediction of 28-day survival. with something measured only on day 1 of life. ${ }^{33}$ Nevertheless, the high AUROC $(\sim 0.9)$ for BOI-d1 was seen with either index or outcome and indeed was consistent even when we excluded the original center (no. 3).

There were differences, both in outcome and BOI-d1 across the European centers. The largest center (no. 3) had the worst outcome. We attribute this in part to it having the largest referral base for antenatally diagnosed fetuses with $\mathrm{CDH}$ for consideration for FETO. Similar survival rates have been reported for other institutions with similarly active fetal medicine programs. ${ }^{34}$ An indirect measure of this is the need for prosthetic patches. Infants with large diaphragmatic defects have a poorer outcome ${ }^{35}$ and are those typically who form the referral group for fetal intervention. By contrast, an overall survival of $>90 \%$ was achieved in one center (no. 1), and it also had one of the highest median BOI-d1 and showed an increased rate of prosthetic patch use. This is certainly comparable with the best reported outcomes both from Europe and North America. 3,4,33

Only one center offered therapeutic intervention (FETO) for selected poor prognosis fetuses over this period beginning in January 2002. Since then, there have been increasing referrals of poor prognosis fetuses from all over Europe and a decrease in overall survival within the center, as previously documented by Sinha et al. ${ }^{27}$ We believe that this selection bias was manifest in several ways. Thus, the patient cohort of center no. 3 had a significantly lower median gestational age and significantly higher rates of patch requirements-all due to the effects of an increasing proportion of poor-prognosis infants surviving to be born. At $60 \%$ overall survival, center no. 3 also had the lowest survival rate and the highest number of patients that had died more than 28 days postsurgery. Severe lung hypoplasia was even the main cause of death in 4 out of the 10 late deaths.

Correlation between LHR, as the most standardized measurement for lung hypoplasia and, therefore, "poor prognosis," and BOI-d1, as predictor for ultimate outcome, was tested and showed that there is a statistical relationship between LHR and BOI-d1. Although not a direct aim of the study, we 
used the BOI-d1 to try and reflect the change in their natural history. Thus, the BOI-d1 in center no. 3 was now similar in the two groups (FETO and non-FETO), and broadly comparable with the other centers despite FETO candidates starting off with lower LHR and being born at a younger gestational age. ${ }^{15}$ These results are consistent with our previous report and we obviously infer that FETO improves lung function. ${ }^{27}$

Tan et al modified our relatively straightforward concept of "best" OI in their study on 24 antenatally diagnosed infants from a United Kingdom center. ${ }^{28}$ They measured OI four times in the first 24 hours and then derived an area under the curve from it-suggesting increased predictive precision. Nonetheless, we did not think this would be repeatable outside of a single center. They also alluded to its use as a serial tool when measured daily. Obviously, OI accuracy as a predictive tool for survival increases with the age of the child as those who have already died are excluded. Nevertheless, calculation of daily BOI summarizes the improvement in gas exchange and stability of the infant presurgery and one could envisage its use in protocols designed to standardize the timing of surgical intervention.

Attempted prediction of survival in $\mathrm{CDH}$ has a long history and many indices have been, at one time, put forward. Just showing a difference between survivors and nonsurvivors, however, is not useful and a more valid appreciation of the value can be made by comparing AUROC values. Thus, the congenital diaphragmatic hernia study group prediction formula, based upon birth weight and Apgar score, has an AUROC of $0.74,{ }^{25}$ the Wilford Hall/Santa Rosa formula (based on best $\mathrm{PaO}_{2}$ and $\mathrm{PaCO}_{2}$ ) has a reported AUROC of $0.87,{ }^{14}$ while a Korean arterial blood gas formula $\left(\mathrm{PaO}_{2}\right.$ and $\left.\mathrm{PaCO}_{2}\right)$ is slightly lower at $0.8 .^{25,36}$ Our BOI-d1 across the centers is consistently around 0.9 . As with any clinical test, determining the appropriate cutoff point has to be balanced by the inverse relationship between sensitivity and specificity and we illustrate our analysis using two cutoff points: 40 and 82 .

In conclusion, this series has confirmed the validity of BOI-d1 when used in a multicenter setting. BOI-d1 is relatively straightforward to calculate at bedside and may have use in indicating the need for more intensive medical (e.g., HFOV) and surgical care (e.g., prosthetic patch need) and formalizing the timing of surgery. On the other hand, BOI-d1 can also be used to characterize the severity of a group of infants with $\mathrm{CDH}$ to enable more appropriate comparison between centers.

\section{Conflict of Interest}

None.

\section{References}

1 Gallot D, Boda C, Ughetto S, et al. Prenatal detection and outcome of congenital diaphragmatic hernia: a French registry-based study. Ultrasound Obstet Gynecol 2007;29(3):276-283

2 Tovar JA. Congenital diaphragmatic hernia. Orphanet J Rare Dis 2012;7:1

3 Boloker J, Bateman DA, Wung J-T, Stolar CJ. Congenital diaphragmatic hernia in 120 infants treated consecutively with permissive hypercapnea/spontaneous respiration/elective repair. J Pediatr Surg 2002;37(3):357-366

4 Downard CD, Jaksic T, Garza JJ, et al. Analysis of an improved survival rate for congenital diaphragmatic hernia. J Pediatr Surg 2003;38(5):729-732

5 Colvin J, Bower C, Dickinson JE, Sokol J. Outcomes of congenital diaphragmatic hernia: a population-based study in Western Australia. Pediatrics 2005;116(3):e356-e363

6 Wynn J, Krishnan U, Aspelund G, et al. Outcomes of congenital diaphragmatic hernia in the modern era of management. J Pediatr 2013;163(1):114-119, e1

7 Kotecha S, Barbato A, Bush A, et al. Congenital diaphragmatic hernia. Eur Respir J 2012;39(4):820-829

8 Reiss I, Schaible T, van den Hout L, et al; CDH EURO Consortium. Standardized postnatal management of infants with congenital diaphragmatic hernia in Europe: the CDH EURO Consortium consensus. Neonatology 2010;98(4):354-364

9 Sluiter I, van de Ven CP, Wijnen RM, Tibboel D. Congenital diaphragmatic hernia: still a moving target. Semin Fetal Neonatal Med 2011;16(3):139-144

10 Deprest J, Gratacos E, Nicolaides KH; FETO Task Group. Fetoscopic tracheal occlusion (FETO) for severe congenital diaphragmatic hernia: evolution of a technique and preliminary results. Ultrasound Obstet Gynecol 2004;24(2):121-126

11 Deprest J, Jani J, Van Schoubroeck D, et al. Current consequences of prenatal diagnosis of congenital diaphragmatic hernia. J Pediatr Surg 2006;41(2):423-430

12 Dekoninck P, Gratacos E, Van Mieghem T, et al. Results of fetal endoscopic tracheal occlusion for congenital diaphragmatic hernia and the set up of the randomized controlled TOTAL trial. Early Hum Dev 2011;87(9):619-624

13 Casaccia G, Crescenzi F, Dotta A, et al. Birth weight and McGoon Index predict mortality in newborn infants with congenital diaphragmatic hernia. J Pediatr Surg 2006;41(1):25-28, discussion $25-28$

14 Congenital Diaphragmatic Hernia Study Group. Estimating disease severity of congenital diaphragmatic hernia in the first 5 minutes of life. J Pediatr Surg 2001;36(1):141-145

15 Ali K, Grigoratos D, Cornelius V, Davenport M, Nicolaides K, Greenough A. Outcome of CDH infants following fetoscopic tracheal occlusion - influence of premature delivery. J Pediatr Surg 2013;48(9):1831-1836

16 Fauza DO, Wilson JM. Congenital diaphragmatic hernia and associated anomalies: their incidence, identification, and impact on prognosis. J Pediatr Surg 1994;29(8):1113-1117

17 Schaible T, Kohl T, Reinshagen K, et al. Right- versus left-sided congenital diaphragmatic hernia: postnatal outcome at a specialized tertiary care center. Pediatr Crit Care Med 2012;13(1):66-71

18 Albanese CT, Lopoo J, Goldstein RB, et al. Fetal liver position and perinatal outcome for congenital diaphragmatic hernia. Prenat Diagn 1998;18(11):1138-1142

19 Yang SH, Nobuhara KK, Keller RL, et al. Reliability of the lung-tohead ratio as a predictor of outcome in fetuses with isolated left congenital diaphragmatic hernia at gestation outside 24-26 weeks. Am J Obstet Gynecol 2007;197(1):e1-e7

20 Jani J, Nicolaides KH, Keller RL, et al; Antenatal-CDH-Registry Group. Observed to expected lung area to head circumference ratio in the prediction of survival in fetuses with isolated diaphragmatic hernia. Ultrasound Obstet Gynecol 2007;30(1): 67-71

21 Jani J, Cannie M, Sonigo P, et al. Value of prenatal magnetic resonance imaging in the prediction of postnatal outcome in fetuses with diaphragmatic hernia. Ultrasound Obstet Gynecol 2008;32(6):793-799

22 Ruano R, Lazar DA, Cass DL, et al. Fetal lung volume and quantification of liver herniation by magnetic resonance imaging in isolated congenital diaphragmatic hernia. Ultrasound Obstet Gynecol 2014;43(6):662-669 
23 Baird R, MacNab YC, Skarsgard ED; Canadian Pediatric Surgery Network. Mortality prediction in congenital diaphragmatic hernia. J Pediatr Surg 2008;43(5):783-787

24 Bohn DJ, James I, Filler RM, et al. The relationship between PaCO2 and ventilation parameters in predicting survival in congenital diaphragmatic hernia. J Pediatr Surg 1984;19(6):666-671

25 Schultz CM, DiGeronimo RJ, Yoder BA; Congenital Diaphragmatic Hernia Study Group. Congenital diaphragmatic hernia: a simplified postnatal predictor of outcome. J Pediatr Surg 2007;42(3): 510-516

26 Hoffman SB, Massaro AN, Gingalewski C, Short BL. Survival in congenital diaphragmatic hernia: use of predictive equations in the ECMO population. Neonatology 2011;99(4):258-265

27 Sinha CK, Islam S, Patel S, Nicolaides K, Greenough A, Davenport M. Congenital diaphragmatic hernia: prognostic indices in the fetal endoluminal tracheal occlusion era. J Pediatr Surg 2009;44(2): 312-316

28 Tan YW, Adamson L, Forster C, Davies B, Sharkey D. Using serial oxygenation index as an objective predictor of survival for antenatally diagnosed congenital diaphragmatic hernia. J Pediatr Surg 2012;47(11):1984-1989

29 Mann PC, Morriss FH Jr, Klein JM. Prediction of survival in infants with congenital diaphragmatic hernia based on stomach position, surgical timing, and oxygenation index. Am J Perinatol 2012; 29(5):383-390
30 UK Collaborative ECMO Trail Group. UK collaborative randomised trial of neonatal extracorporeal membrane oxygenation. Lancet 1996;348(9020):75-82

31 Trachsel D, McCrindle BW, Nakagawa S, Bohn D. Oxygenation index predicts outcome in children with acute hypoxemic respiratory failure. Am J Respir Crit Care Med 2005;172(2):206-211

32 Zani A, Sellars M, Allen P, et al. Tracheomegaly in infants with severe congenital diaphragmatic hernia treated with fetal endoluminal tracheal occlusion. J Pediatr 2014;164(6):1311-1315

33 van den Hout L, Sluiter I, Gischler S, et al. Can we improve outcome of congenital diaphragmatic hernia? Pediatr Surg Int 2009;25(9): 733-743

34 Hedrick HL, Danzer E, Merchant A, et al. Liver position and lung-tohead ratio for prediction of extracorporeal membrane oxygenation and survival in isolated left congenital diaphragmatic hernia. Am J Obstet Gynecol 2007;197(4):e1-e4

35 Morini F, Valfrè L, Capolupo I, Lally KP, Lally PA, Bagolan P; Congenital Diaphragmatic Hernia Study Group. Congenital diaphragmatic hernia: defect size correlates with developmental defect. J Pediatr Surg 2013;48(6):1177-1182

36 Park HW, Lee BS, Lim G, Choi YS, Kim EA, Kim KS. A simplified formula using early blood gas analysis can predict survival outcomes and the requirements for extracorporeal membrane oxygenation in congenital diaphragmatic hernia. J Korean Med Sci 2013;28(6):924-928 